\title{
Editor's Introduction for the Special Issue on Jewish Demography in the United States
}

\author{
Samuel Heilman
}

Published online: 26 April 2013

(C) Springer Science+Business Media Dordrecht 2013

This special issue on Jewish population and demography, part of our regular dedication of one issue every couple of years on these questions, has been a long time in coming. It began as a conference at Brandeis University in 2011 in which scholars and thinkers in the field, largely at the urging of this journal, convened to share ideas on the questions of how many Jews there were, how we would explore that question, what the problems were that confronted researchers, and how sense could be made out of what was learned. Those who gathered at Brandeis also included people who are not commonly engaged in demographic or population studies but are convinced that there is a need to make this research accessible and relevant to a wider audience than simply those who toil in this field.

Some of the ideas and matters discussed at that conference as well as others generated by it are available in the papers that make up this volume, guest edited by Professors Sergio DellaPergola of the Hebrew University in Jerusalem and Leonard Saxe of the Cohen Center for Modern Jewish Studies and the Steinhardt Social Research Institute at Brandeis University. The effort to transform conference papers and to take ideas they have generated and make them into an integrated whole of a special issue of Contemporary Jewry was not an easy one and, as those involved in the process will attest, more complicated and time consuming than anyone expected at the outset. The results of the effort, for a time online, are now joined in a single volume that we all hope will serve as an important resource for students, scholars, and the informed and interested public — at least until our next issue on the subject in a couple of years.

Jews have been counting themselves since the exodus from Egypt, and just as long there have been questions about the accuracy and completeness of those counts. In that sense, not a lot has changed in the long course of Jewish history. But we have always understood that while the question of what constitutes Jewish

S. Heilman (西)

Department of Sociology, CUNY Graduate Center, New York, NY, USA

e-mail: scheilman@gmail.com 
identity and activity is essential and critical, the question of how many there are for whom it is such, is no less important.

While my common practice in this space is to offer snapshots of the articles in the issue and try to knit it all together, that role will be filled by our guest editors to whom I offer my thanks for their work here. The readers will of course judge for themselves what they have learned, but I trust it will be quite a bit, beginning with an essay by one of the pioneers of the field, Sidney Goldstein, and through a series of researchers both young and older who have followed in his path.

In forthcoming issues, we shall be seeing a series of articles on graphic Jewish novels and their impact, a special issue on Jewish music, and a wide array of subjects that broaden our appreciation of the social scientific study of contemporary Jewry. As always, we shall be 'online first.' In addition, we invite submissions from young and senior scholars who want a voice in the field and who have ideas and research to share. And of course, we encourage all of our readers both to be members of the Association for the Social Scientific Study of Jewry (assj.org) and to see to it that their libraries are subscribers. 